\title{
ANALISIS FAKTOR-FAKTOR YANG BERPENGARUH TERHADAP INTERNAL SERVICE QUALITY (STUDI KASUS DI PT. ASA YOGYAKARTA)
}

\author{
Lucia Yemi Dinaria \\ Endah Utami \\ Universitas Ahmad Dahlan \\ e-mail: endahut@yahoo.com
}

\begin{abstract}
ABSTRAK
This study revolves about the Internal Service Quality in PT. ASA Yogyakarta engaged in the production of golf gloves. In the face of strict quality requirements in global markets, the management of PT. ASA Yogyakarta expected to be able to create a high quality product that can meet the needs and desires of its customers, and provides high customer satisfaction. In an attempt to give the best quality to the consumer role of internal service quality is very important and strategic, this is due to embody the role of quality starts from the internal customer. This study aims to analyze the effect of internal service quality, leadership, customer orientation, organizational commitment, and job satisfaction of internal service quality. The results of this research is based on an assessment of the employee survey results that the internal communication, leadership, customer orientation, organizational commitment and customer satisfaction are silmutan significant effect on internal service quality. This suggests that the good and bad internal service quality in Yogyakarta, 94\% PT ASA is determined by the internal communication, leadership, customer orientation, organizational commitment and job satisfaction. While the rest are caused by other variables not included in this study.

Keywords: internal service quality, internal communicatin, leadership, customer orientation, organizational commitment, job satisfaction
\end{abstract}

\section{PENDAHULUAN}

PT. ASA Yogyakarta merupakan salah satu perusahaan yang bergerak dalam produksi sarung tangan golf. Jika ditinjau dari jangkauan pemasarannya, PT. ASA Yogyakarta dapat dikategorikan sebagai perusahaan global karena produk yang dihasilkan perusahaan tersebut sebagian besar dipasarkan di pasar internasional seperti
Amerika, Perancis, Belanda, Inggris dan beberapa negara Eropa dan Amerika lainnya. Masalah kualitas produk di pasar global merupakan masalah utama, yang sangat menentukan keberhasilan suatu produk. Dalam rangka menghadapi ketatnya persyaratan kualitas di pasar global, maka pihak manajemen PT.ASA Yogyakarta dituntut harus mampu menciptakan produk yang berkualitas tinggi sehingga dapat memenuhi kebutuhan dan keinginan pelanggannya; serta memberikan kepuasan pelanggan yang tinggi. 
Masalah utama yang dihadapi PT. ASA Yogyakarta saat ini adalah kualitas pelayanan internal. Pelayanan yang diberikan karyawan kepada karyawan lain masih tergolong belum optimal. Hal ini diindikasikan mengakibatkan rendahnya produktifitas karyawan serta rendahnya semangat kerja karyawan, Akibat lain yang muncul adalah sering terdapat penumpukan barang setengah jadi, sehingga mengakibatkan produk yang dihasilkan tidak sesuai dengan perencanaan awal. Hal-hal tersebut akhirnya mengakibatkan tidak dapat tercapainya target produksi. Permasalahan tersebut jika dikaitkan dengan konsep internal service quality, maka implikasinya adalah manajemen PT ASA Yogyakarta harus dapat menciptakan internal service quality yang tinggi dalam lingkungan perusahaan tersebut. Untuk dapat meningkatkan internal service quality maka manajemen harus mampu mengidentifikasi faktor-faktor apa saja yang mempengaruhi internal service quality.

\section{REVIEW LITERATUR DAN HIPOTESIS}

Variabel penting yang menjadi tolok ukur yang digunakan untuk mengidentifikasi baik buruknya kualitas dari pelanggan internal adalah internal service quality atau kualitas pelayanan internal. Menurut Kang (2002), internal service quality adalah kualitas dari pelayanan yang diberikan oleh departemen tertentu atau karyawan yang bekerja di dalamnya kepada departemen atau karyawan lain pada perusahaan yang sama. Dengan demikian departemen atau karyawan pada dasarnya merupakan pengguna dan sekaligus juga pemberi pelayanan terhadap yang lain; yang terlibat secara langsung atau berpartisipasi dalam hubungan produsen-pelanggan (producercustomer relationship) (Boshoff, C. and Mels, G. 1996). Oleh karena internal service quality merupakan variabel yang penting dan strategis dalam mendukung pencapaian tujuan perusahaan; khu- susnya melalui pengaruhnya terhadap kepuasan pelanggan; maka secara umum dapat dikatakan bahwa pihak manejemen harus mampu mendeteksi, mengukur serta menganalisis faktor-faktor apa saja yang dapat mempengaruhi tinggi rendahnya internal service quality.

Berdasarkan bukti empiris yaitu hasil penelitian yang pernah dilakukan oleh Fletcher (1999) di Afrika Selatan; internal service quality dipengaruhi oleh internal communication atau komunikasi internal, dan leadership atau kepemimpinan. Internal communication adalah komunikasi yang terjadi di dalam perusahaan antara karyawan dengan rekan kerja dan karyawan dengan atasan atu supervisor. Leadership atau kepemimpinan dalam hal ini adalah kepemimpinan kualitas, yang berkaitan dengan penetapan kebijakan kualitas, penetapan dan penyebarluasan sasaran kualitas, penyiapan sumberdaya, penyiapan masalah pelatihan untuk mencari solusi terhadap masalah kualitas yang dihadapi perusahaan, serta memberikan pemberian penghargaan atas prestasi karyawan.

Menurut Gaspersz (2005), Leadership (kepemimpinan) adalah proses untuk mempengaruhi orang lain agar memahami dan setuju dengan apa yang perlu dilakukan dan bagaimana tugas itu dilakukan secara efektif, serta proses untuk memfasilitasi upaya individu dan kelompok untuk mencapai tujuan bersama . Dalam konteks manajemen kualitas kepemimpinan digunakan untuk mengidentifikasi dan kemudian menghilangkan penyebab kegagalan, serta membantu karyawan agar mampu mengerjakan pekerjaan secara lebih baik dengan memperhatikan efektivitas (pencapaian tujuan) dan efisiensi (penggunaan biaya) dalam setiap aktivitas yang dilakukan. Dalam konteks manajemen kualitas dikenal dua jenis pelanggan yaitu pelanggan eksternal (external customer) dan pelanggan internal (internalcustomer). Pelanggan eksternal adalah pembeli atau 
pemakai akhir produk atau sering disebut dengan pelanggan nyata (real customer); sedangkan pelanggan internal (internalcustomer) adalah orang dalam perusahaan dan memiliki pengaruh pada performasi pekerjaan.

Konsep internal service quality pada dasarnya dikembangkan dari konsep internal marketing. Konsep internal marketing dikemukakan pertama kali oleh Kang (2002). Internal marketing pada awalnya merupakan suatu pendekatan (approach) di dalam manajemen jasa yang menggabungkan konsep pemasaran tradisional dengan elemen-elemen marketing mix yang diaplikasikan dalam lingkup perusahaan dan karyawannya untuk meningkatkan internal market relationship. Internal marketing merupakan suatu pendekatan manajemen yang mampu memotivasi seluruh karyawan untuk memanfaatkan kemampuannya untuk memenuhi dan memuaskan kebutuhan pelanggan eksternal.

Penelitian yang akan dilakukan ini pada dasarnya merupakan replikasi dari penelitian yang pernah dilakukan oleh Fletcher (1999) tersebut. Perbedaan utamanya terletak pada lokasi penelitian, di mana penelitian Fletcher (1999) dilakukan di Afrika Selatan; sedangkan penelitian ini dilakukan di Yogyakarta. Perbedaan lainnya adalah pada obyek yang diteliti; dalam penelitian yang dilakukan oleh Fletcher (1999); obyeknya adalah karyawan yang bekerja pada perusahaan transportasi sedangkan penelitian ini obyeknya adalah karyawan yang bekerja pada perusahaan manufaktur.

\section{Internal Communication}

Komunikasi (communication) adalah suatu proses pertukaran informasi antara pengirim dan penerima, dan kesimpulan (persepsi) makna antara individu-individu yang terlibat (Kreitner, 2005). Sedangkan menurut Liliweri (1997) komunikasi merupakan kegiatan komunikator dengan komunikan yang mempertukarkan dan memberikan makna yang sama atas informasi untuk suatu tujuan tertentu, melalui media, metode, teknik, atau cara-cara yang telah ditetapkan. Komunikasi adalah peralihan suatu pesan (informasi, gagasan, emosi, maksud, perasaan, atau segala sesuatu baik yang diterima maupun dipahami (Goetsch, 2002)

Internal communication atau komunikasi internal merupakan proses komunikasi yang berlangsung dalam suatu organisasi, atau sering disebut juga dengan istilah komunikasi organisasi. Komunikasi internal atau komunikasi organisasi dapat dipahami sebagai proses pertukaran gagasan, pendapat, informasi, instruksi dan sejenisnya yang dilakukan secara sengaja oleh anggota organisasi untuk mewujudkan hubungan yang bersifat personal dan impersonal melalui simbol-simbol atau tanda-tanda tertentu untuk mencapai tujuan organisasi (Liliweri,1997). Secara fungsional komunikasi internal atau komunikasi organisasi dapat didefinisikan sebagai pertunjukan dan penafsiran pesan di antara unit-unit komunikasi yang merupakan bagian dari suatu organisasi tertentu (Pace, 1998). Sedangkan secara interpretif maka komunikasi organisasi dapat didefinisikan sebagai suatu proses penciptaan makna atas interaksi yang menciptakan, memelihara, dan mengubah organisasi.

Komunikasi internal dalam suatu organisasi pada dasarnya memiliki empat fungsi utama yaitu: pengendalian, motivasi, pengungkapan emosi dan informasi (Robbins, 2006).. Sedangkan menurut Liliweri (Liliweri, 1997) komunikasi merupakan kegiatan komunikator dengan komunikan yang mempertukarkan dan memberikan makna yang sama atas informasi untuk suatu tujuan tertentu, melalui media, metode, teknik, atau caracara yang telah ditetapkan. Komunikasi adalah peralihan suatu pesan (informasi, gagasan, emosi, maksud, perasaan, atau segala sesuatu baik yang diterima maupun dipahami (Goetsch, 2002) 
Internal communication atau komunikasi internal merupakan proses komunikasi yang berlangsung dalam suatu organisasi, atau sering disebut juga dengan istilah komunikasi organisasi. Komunikasi internal atau komunikasi organisasi dapat dipahami sebagai proses pertukaran gagasan, pendapat, informasi, instruksi dan sejenisnya yang dilakukan secara sengaja oleh anggota organisasi untuk mewujudkan hubungan yang bersifat personal dan impersonal melalui simbol-simbol atau tanda-tanda tertentu untuk mencapai tujuan organisasi (Liliweri,1997). Secara fungsional komunikasi internal atau komunikasi organisasi dapat didefinisikan sebagai pertunjukan dan penafsiran pesan di antara unit-unit komunikasi yang merupakan bagian dari suatu organisasi tertentu (Pace, 1998). Sedangkan secara interpretif maka komunikasi organisasi dapat didefinisikan sebagai suatu proses penciptaan makna atas interaksi yang menciptakan, memelihara, dan mengubah organisasi.

Komunikasi internal dalam suatu organisasi pada dasarnya memiliki empat fungsi utama yaitu: pengendalian, motivasi, pengungkapan emosi dan informasi (Robbins,2006). Sedangkan menurut Liliweri (1997) komunikasi merupakan kegiatan komunikator dengan komunikan yang mempertukarkan dan memberikan makna yang sama atas informasi untuk suatu tujuan tertentu, melalui media, metode, teknik, atau cara-cara yang telah ditetapkan. Komunikasi adalah peralihan suatu pesan (informasi, gagasan, emosi, maksud, perasaan, atau segala sesuatu baik yang diterima maupun dipahami (Goetsch,2002)

Internal communication atau komunikasi internal merupakan proses komunikasi yang berlangsung dalam suatu organisasi, atau sering disebut juga dengan istilah komunikasi organisasi. Komunikasi internal atau komunikasi organisasi dapat dipahami sebagai proses pertukaran gagasan, pendapat, informasi, instruksi dan sejenisnya yang dilakukan secara sengaja oleh anggota organisasi untuk mewujudkan hubungan yang bersifat personal dan impersonal melalui simbol-simbol atau tanda-tanda tertentu untuk mencapai tujuan organisasi (Liliweri, 1997). Secara fungsional komunikasi internal atau komunikasi organisasi dapat didefinisikan sebagai pertunjukan dan penafsiran pesan di antara unit-unit komunikasi yang merupakan bagian dari suatu organisasi tertentu (Pace, 1998). Sedangkan secara interpretif maka komunikasi organisasi dapat didefinisikan sebagai suatu proses penciptaan makna atas interaksi yang menciptakan, memelihara, dan mengubah organisasi.

Komunikasi internal dalam suatu organisasi pada dasarnya memiliki empat fungsi utama yaitu: pengendalian, motivasi, pengungkapan emosi dan informasi (Robbins, 2006)

Penelitian ini bertujuan 1) Untuk mengetahui pengaruh internal communication, leadership, customer orientation, komitmen organisasional dan kepuasan kerja secara simultan terhadap internal service quality; 2) Untuk mengetahui pengaruh internal communication secara parsial terhadap internal service qualit; 3).Untuk mengetahui pengaruh leadership secara parsial terhadap internal service quality; 4) Untuk mengetahui pengaruh customer orientation secara parsial terhadap internal service quality; 5) Untuk mengetahui pengaruh komitmen organisasional secara parsial terhadap internal service quality; 6)Untuk mengetahui pengaruh kepuasan kerja secara parsial terhadap internal service quality.

\section{Hipotesis}

$\mathrm{H}_{1}$ : Internal communication, Leadership, Customer Orientation, Komitmen Organisasional dan Kepuasan kerja secara simulatan berpengaruh positif terhadap Internal Service Quality. 
$\mathrm{H}_{2}$ : Internal communicationberpengaruh positif terhadap Internal Service Quality.

$\mathrm{H}_{3}$ : Leadershipberpengaruh positif terhadap Internal Service Quality.

$\mathrm{H}_{4}$ : Customer orientation berpengaruh positif terhadap Internal Service Quality.

$\mathrm{H}_{5}$ : Komitmen organisasional berpengaruh positif terhadap Internal Service Quality.

$\mathrm{H}_{6}$ : Kepuasan kerja berpengaruh positif terhadap Internal Service Quality.

\section{METODE PENELITIAN}

Objek dalam penelitian ini adalah karyawan tetap perusahaan PT. ASA Yogyakarta.Instrumen yang digunakan untuk mengukur variabel pe-nelitian ini mengadopsi kuesioner yang pernah digunakan Melani Fletcher yang telah disesuaikan dengan kondisi obyek penelitian.

\section{Instrumen Penelitian}

Alat ukur yang digunakan adalah kuesioner sedangkan pengukurannya menggunakan skala Linkert. Skala Linkert adalah instrumen yang digunakan untuk meminta responden agar memberikan respon terhadap beberapa statement.Skala pengukuran yang digunakan dalam kuesioner tersebut adalah skala Likert dengan interval Sangat Tidak Setuju (STS, skor $=1)$ hingga Sangat Setuju (SS, skor $=5$ ).

Adapun Indikator Variabel Penelitian adalah sebagai berikut ;

Penentuan Indikator Variabel penelitian Internal Service Quality peneliti mengacu pada 5 Dimensi kualitas layanan yang dirumuskan oleh Parasuraman dkk, yaitu

1) Reliabilitas (Reliability), yakni kemampuan memberikan layanan yang dijanjikan dengan segera ,akurat dan memuaskan.
2) Daya tanggap (Responsiveness), yaitu keinginan para staff untuk membantu para pelanggan dan memberi layanan dengan tanggap.

3) Jaminan (Assurance), yaitu mencakup pengetahuan, kompetensi, kesopanan, dan sifat dapat dipercaya yang dimiliki para staff, bebas dari bahaya, resiko atau keragu-raguan.

4) Empati (Empathy), meliputi dalam menjalin relasi, komunikasi yang baik,perhatian pribadi, dan pemahaman atas kebutuhan individual pelanggan.

5) Bukti fisik (Tangibles), meliputi fasilitas fisik, perlengkapan, pegawai, dan sarana komunikasi.

Adapun variabel penelitian untuk Internal Communication, Leadership, Customer Orientation, Komitmen Organisasi dan Kepuasan Kerja sebagai berikut :

Internal Communication, meliputi Komunikasi ke bawah, Komunikasi ke atas, Komunikasi horizontal.

Komunikasi ke bawah yaitu adanya komunikasi yang dilakukan pimpinan kepada bawahan terhadap

1. Jenis Pekerjaan

2. Deskripsi pekerjaan

3. Prosedur pelaksanaan pekerjaan

4. Tujuan pekerjaan

5. Hubungan satu pekerjaan dengan pekerjaan lainnya

6. Hubungan pekerjaan dengan tujuan perusahaan

7. Loyalitas karyawan terhadap perusahaan

8. Motivasi kerja

9. Moralitas pekerja

10. Tata tertib perusahaan

11. Teguran terhadap pekerjaan yang tidak memenuhi standar perusahaan 
Komunikasi ke atas yaitu diperbolehkannya bawahan mengkomunikasikan kepada atasan dalam hal :

1. Hasil pekerjaan

2. Kemajuan pekerjaan

3. Rencana kerja

4. Permasalahan pekerjaan

5. Penyampaian saran

6. Penilaian pekerjaannya

Komunikasi horizontal yaitu komunikasi diantara sesama karyawan dalam hal

1. Koordinasi untuk pemecahan masalah

2. Pemberian informasi untuk perencanaan dan pelaksanaan pekerjaan

3. Penyelesaian konflik

4. Hubungan interpersonal

5. Peningkatan motivasi

\section{Leadership}

1. Kemampuan penyelesaian masalah

2. Kemampuan melakukan pengarahan

3. Keadilan

4. Sikap hormat bawahan

5. Kemampuan pencarian solusi dan tindakan

6. Kemampuan pemberian motivasi, perhatian

Customer Orientation, yaitu orientasi karyawan terhadap

Pengetahuan, pengalaman di bidangnya, kemahiran, kemampuan sosial, komitmen, kualitas pelayanan

Komitmen Organisasional, meliputi komitmen karyawan terhadap perusahaan,loyalitas karyawan terhadap perusahaan

Kepuasan Kerja, meliputi peningkatan karier,hubungan personal dengan karyawan lain, pengembangan diri karyawan, aktualisasi diri, pemenuhan kebutuhan finansial dan non finansial

Populasi penelitian ini adalah seluruh karyawan tetap PT ASA, sedangkan sampel penelitian sebesar 121 orang.
Metode analisis data yang digunakan dalam penelitian ini adalah analisis regresi linear berganda. Adapun model regresi tersebut dapat dituliskan sebagai berikut:

$\mathrm{Y}=\mathrm{b}_{0}+\mathrm{b}_{1} \mathrm{X}_{1}+\mathrm{b}_{2} \mathrm{X}_{2}+\mathrm{b}_{3} \mathrm{X}_{3}+\mathrm{b}_{4} \mathrm{X}_{4}+\mathrm{b}_{5} \mathrm{X}_{5}+\mathrm{e}$

Keterangan:

$\mathrm{Y}=$ Internal Service Quality

$\mathrm{X} 1=$ Internal Communication

$\mathrm{X}_{2}=$ Leadership

$\mathrm{X}_{3}=$ Customer Orientation

$\mathrm{X}_{4}=$ Komitmen Organisasional

$\mathrm{X}_{5}=$ Kepuasan Kerja

bo $=$ Intersep regresi

$\mathrm{b}_{1}=$ Koefisien regresi Internal Communication

$\mathrm{b}_{2}=$ Koefisien regresi Leadership

$\mathrm{b}_{3}=$ Koefisien regresi Customer Orientation

$\mathrm{b}_{4}=$ Koefisien regresi Komitmen Organisasional

$\mathrm{b}_{5}=$ Koefisien regresi Kepuasan Kerja

$\mathrm{e}=$ Disturbance error

Penggunaan terhadap hasil analis regresi tersebut harus dipastikan bahwa model telah memenuhi asumsi yang mendasarinya. Uji asumsi yang dikenakan terhadap model tersebut meliputi: (1) uji normalitas data, (2) uji linearitas, dan (3) uji asumsi klasik. Dalam asumsi klasik, uji yang dikenakan hanya uji multikolinearitas dan uji heteroskedastisitas; sedangkan uji autokorelasi tidak dilakukan karena data yang digunakan dalam penelitian ini merupakan data cross section bukan data time series.

\section{Uji normalitas}

Uji normalitas ini perlu dilakukan dalam analisis multivariate (termasuk analisis regresi linear berganda). Hal ini disebabkan jika data menyimpang cukup besar terhadap normalitas maka statistik yang dihasilkan ( $\mathrm{F}$ dan $\mathrm{t}$ ) menjadi tidak valid. Pengujian terhadap normalitas data secara univariat ini dilakukan dengan 
menggunakan metode Kolmogorov-Smirnov. Kriteria pengujiannya adalah, jika statistik KS tidak signifikan $(p>\alpha)$ maka distribusi data yang uji adalah normal.

\section{Uji linearitas}

Uji linearitas ini perlu dilakukan mengingat model regresi yang digunakan merupakan regresi linear. Linearitas tersebut merujuk pada hubungan linear antara $\mathrm{X}$ (variabel bebas) dengan variabel terikat (Y) . Secara logis, jika hubungan antara variabel bebas dengan variabel terikat bukan merupakan hubungan yang linear berarti tidak dapat menggunakan model regresi linear tetapi menggunakan model regresi non linear. Pengujian terhadap linearitas hubungan antara suatu variabel bebas dengan variabel bebas dapat dilakukan dengan menggunakan analisis regresi linear sederhana. Kriterianya adalah, jika model regresi linear sederhana antara $\mathrm{X}$ dengan $\mathrm{Y}$ memiliki statistik $F$ yang signifikan $(p<\alpha)$, maka hubungan antara $\mathrm{X}$ dengan $\mathrm{Y}$ tersebut bersifat linear.

\section{Uji multikolinearitas}

Dalam penelitian ini uji multikolinearitas dilakukan dengan menggunakan indikator VIF (Variance Inflating Factor). Kriterianya adalah, jika suatu variabel bebas memiliki nilai $\mathrm{VIF}<10$ maka variabel bebas tersebut mengalami tidak multikolinearitas dengan variabel bebas yang lain.

\section{Uji heteroskedasitas}

Uji heteroskedastisitas dalam penelitian ini dilakukan dengan menggunakan metode korelasi Spearman. Kriterianya adalah, jika suatu variabel dalam model regresi Park memiliki koefisien regresi yang tidak signifikan maka variabel bebas tersebut tidak mengalami heteroskedasitas.

\section{HASIL PENELITIAN DAN PEMBAHASAN}

Berikut hasil uji validitas dan reliabilitas terhadap kuesioner Internal SERVQUAL,

\section{Tabel 1}

\section{Hasil Uji Validitas dan Reliabilitas}

Kuesioner Internal Service Quality

\begin{tabular}{|c|c|c|c|}
\hline $\begin{array}{c}\text { Item } \\
\text { Pernyataan }\end{array}$ & $\begin{array}{c}\text { Koefisien } \\
\text { Validitas }\end{array}$ & $\begin{array}{c}\text { Nilai } \\
\text { Batas }\end{array}$ & Keterangan \\
\hline SQ1 & 0,533 & 0,50 & Valid \\
SQ2 & 0,601 & 0,50 & Valid \\
SQ3 & 0,627 & 0,50 & Valid \\
SQ4 & 0,713 & 0,50 & Valid \\
SQ5 & 0,682 & 0,50 & Valid \\
SQ6 & 0,613 & 0,50 & Valid \\
SQ7 & 0,511 & 0,50 & Valid \\
SQ8 & 0,543 & 0,50 & Valid \\
SQ9 & 0,511 & 0,50 & Valid \\
SQ10 & 0,514 & 0,50 & Valid \\
SQ11 & 0,587 & 0,50 & Valid \\
SQ12 & 0,667 & 0,50 & Valid \\
SQ13 & 0,773 & 0,50 & Valid \\
SQ14 & 0,550 & 0,50 & Valid \\
SQ15 & 0,526 & 0,50 & Valid \\
SQ16 & 0,563 & 0,50 & Valid \\
SQ17 & 0,574 & 0,50 & Valid \\
SQ18 & 0,505 & 0,50 & Valid \\
SQ19 & 0,543 & 0,50 & Valid \\
SQ20 & 0,530 & 0,50 & Valid \\
SQ21 & 0,787 & 0,50 & Valid \\
\hline \multicolumn{4}{|l|}{ Koefisien reliabilitas =0,815 } \\
\hline
\end{tabular}

Sumber: Data primer 2010 (diolah).

Hasil uji validitas dan reliabilitas terhadap kuesioner Internal Service Quality yang disajikan dalam tabel 1 menunjukkan bahwa, masingmasing item pernyataan dalam kuesioner tersebut memiliki koefisien validitas $>0,50$; sehingga dapat disimpulkan bahwa masing-masing item pernyataan tersebut valid.

Koefisien reliabilitas kuesioner tersebut sebesar 0,815; oleh karena lebih besar dari 0,60 maka disimpulkan bahwa kuesioner tersebut reliabel. Hasil uji validitas dan reliabilitas ini menunjukkan bahwa kuesioner Internal Service 
Quality layak digunakan sebagai instrumen pengumpul data.

\section{Kuesioner Internal Communication}

Variabel Internal communication diukur dengan menggunakan 23 item pernyataan.Hasil uji validitas dan reliabilitas terhadap kuesioner tersebut disajikan dalam tabel 2 berikut.

\section{Tabel 2}

\section{Hasil Uji Validitas dan Reliabilitas} Kuesioner Internal Communication

\begin{tabular}{|c|c|c|c|}
\hline $\begin{array}{c}\text { Item } \\
\text { Pernyataan }\end{array}$ & $\begin{array}{c}\text { Koefisien } \\
\text { Validitas }\end{array}$ & $\begin{array}{c}\text { Nilai } \\
\text { Batas }\end{array}$ & Keterangan \\
\hline IC1 & 0,808 & 0,50 & Valid \\
IC2 & 0,635 & 0,50 & Valid \\
IC3 & 0,593 & 0,50 & Valid \\
IC4 & 0,770 & 0,50 & Valid \\
IC5 & 0,729 & 0,50 & Valid \\
IC6 & 0,661 & 0,50 & Valid \\
IC7 & 0,588 & 0,50 & Valid \\
IC8 & 0,532 & 0,50 & Valid \\
IC9 & 0,780 & 0,50 & Valid \\
IC10 & 0,748 & 0,50 & Valid \\
IC11 & 0,635 & 0,50 & Valid \\
IC12 & 0,576 & 0,50 & Valid \\
IC13 & 0,543 & 0,50 & Valid \\
IC14 & 0,544 & 0,50 & Valid \\
IC15 & 0,504 & 0,50 & Valid \\
IC16 & 0,541 & 0,50 & Valid \\
IC17 & 0,701 & 0,50 & Valid \\
IC18 & 0,541 & 0,50 & Valid \\
IC19 & 0,559 & 0,50 & Valid \\
IC20 & 0,516 & 0,50 & Valid \\
IC21 & 0,511 & 0,50 & Valid \\
IC22 & 0,749 & 0,50 & Valid \\
IC23 & 0,580 & 0,50 & Valid \\
\hline \multicolumn{5}{|r}{ Koefisien reliabilitas $=0,832$} & \\
\hline
\end{tabular}

Sumber: Data primer 2010 (diolah).

Hasil uji validitas dan reliabilitas terhadap kuesioner Internal communication yang disajikan dalam tabel 2 menunjukkan bahwa, masingmasing item pernyataan dalam kuesioner tersebut memiliki koefisien validitas $>0,50$; sehingga dapat disimpulkan bahwa masing-masing item pernyataan tersebut valid.

Koefisien reliabilitas kuesioner tersebut sebesar 0,832; oleh karena lebih besar dari 0,60 maka disimpulkan bahwa kuesioner tersebut reliabel.
Hasil uji validitas dan reliabilitas ini menunjukkan bahwa kuesioner Internal communication layak digunakan sebagai instrumen pengumpul data.

\section{Kuesioner Leadership}

Variabel Leadership diukur dengan menggunakan 15 item pernyataan.Hasil uji validitas dan reliabilitas terhadap kuesioner tersebut disajikan dalam tabel 3 berikut.

\section{Tabel 3}

\section{Hasil Uji Validitas dan Reliabilitas Kuesioner Leadership}

\begin{tabular}{|c|c|c|c|}
\hline $\begin{array}{c}\text { Item } \\
\text { Pernyataan }\end{array}$ & $\begin{array}{c}\text { Koefisien } \\
\text { Validitas }\end{array}$ & $\begin{array}{c}\text { Nilai } \\
\text { Batas }\end{array}$ & Keterangan \\
\hline LD1 & 0,700 & 0,50 & Valid \\
LD2 & 0,549 & 0,50 & Valid \\
LD3 & 0,675 & 0,50 & Valid \\
LD4 & 0,622 & 0,50 & Valid \\
LD5 & 0,562 & 0,50 & Valid \\
LD6 & 0,639 & 0,50 & Valid \\
LD7 & 0,663 & 0,50 & Valid \\
LD8 & 0,598 & 0,50 & Valid \\
LD9 & 0,801 & 0,50 & Valid \\
LD10 & 0,849 & 0,50 & Valid \\
LD11 & 0,688 & 0,50 & Valid \\
LD12 & 0,773 & 0,50 & Valid \\
LD13 & 0,534 & 0,50 & Valid \\
LD14 & 0,629 & 0,50 & Valid \\
LD15 & 0,662 & 0,50 & Valid \\
\hline \multicolumn{4}{|c}{ Koefisien reliabilitas $=0,765$} \\
\hline
\end{tabular}

Sumber: Data primer 2010 (diolah).

Hasil uji validitas dan reliabilitas terhadap kuesioner Leadership yang disajikan dalam tabel 3 menunjukkan bahwa, masing-masing item pernyataan dalam kuesioner tersebut memiliki koefisien validitas $>0,50$; sehingga dapat disimpulkan bahwa masing-masing item pernyataan tersebut valid.

Koefisien reliabilitas kuesioner tersebut sebesar 0,765; oleh karena lebih besar dari 0,60 maka disimpulkan bahwa kuesioner tersebut reliabel. Hasil uji validitas dan reliabilitas ini menunjukkan bahwa kuesioner Leadership layak digunakan sebagai instrumen pengumpul data. 


\section{Kuesioner Customer orientation}

Variabel Customer orientation diukur dengan menggunakan 9 item pernyataan. Hasil uji validitas dan reliabilitas terhadap kuesioner tersebut disajikan dalam tabel 4 berikut.

\section{Tabel 4}

Hasil Uji Validitas dan Reliabilitas Kuesioner Customer orientation

\begin{tabular}{|c|c|c|c|}
\hline $\begin{array}{c}\text { Item } \\
\text { Pernyataan }\end{array}$ & $\begin{array}{c}\text { Koefisien } \\
\text { Validitas }\end{array}$ & $\begin{array}{c}\text { Nilai } \\
\text { Batas }\end{array}$ & Keterangan \\
\hline CO1 & 0,594 & 0,50 & Valid \\
CO2 & 0,732 & 0,50 & Valid \\
CO3 & 0,791 & 0,50 & Valid \\
CO4 & 0,819 & 0,50 & Valid \\
CO5 & 0,615 & 0,50 & Valid \\
CO6 & 0,676 & 0,50 & Valid \\
CO7 & 0,642 & 0,50 & Valid \\
CO8 & 0,504 & 0,50 & Valid \\
CO9 & 0,517 & 0,50 & Valid \\
\hline \multicolumn{3}{|c}{ Koefisien reliabilitas $=0,647$} \\
\hline
\end{tabular}

Sumber: Data primer 2010 (diolah).

Hasil uji validitas dan reliabilitas terhadap kuesioner Customer orientation yang disajikan dalam tabel 4 menunjukkan bahwa, masingmasing item pernyataan dalam kuesioner tersebut memiliki koefisien validitas $>0,50$; sehingga dapat disimpulkan bahwa masing-masing item pernyataan tersebut valid.

Koefisien reliabilitas kuesioner tersebut sebesar 0,647; oleh karena lebih besar dari 0,60 maka disimpulkan bahwa kuesioner tersebut reliabel. Hasil uji validitas dan reliabilitas ini menunjukkan bahwa kuesioner Customer orientation layak digunakan sebagai instrumen pengumpul data.

\section{Kuesioner Komitmen Organisasional}

Variabel Komitmen organisasional diukur dengan menggunakan 12 item pernyataan. Hasil uji validitas dan reliabilitas terhadap kuesioner tersebut disajikan dalam tabel 5 berikut.
Tabel 5

Hasil Uji Validitas dan Reliabilitas Kuesioner Komitmen Organisasional

\begin{tabular}{|c|c|c|c|}
\hline $\begin{array}{c}\text { Item } \\
\text { Pernyataan }\end{array}$ & $\begin{array}{c}\text { Koefisien } \\
\text { Validitas }\end{array}$ & $\begin{array}{c}\text { Nilai } \\
\text { Batas }\end{array}$ & Keterangan \\
\hline KO1 & 0,579 & 0,50 & Valid \\
KO2 & 0,513 & 0,50 & Valid \\
KO3 & 0,559 & 0,50 & Valid \\
KO4 & 0,537 & 0,50 & Valid \\
KO5 & 0,588 & 0,50 & Valid \\
KO6 & 0,735 & 0,50 & Valid \\
KO7 & 0,650 & 0,50 & Valid \\
KO8 & 0,533 & 0,50 & Valid \\
KO9 & 0,551 & 0,50 & Valid \\
KO10 & 0,556 & 0,50 & Valid \\
KO11 & 0,649 & 0,50 & Valid \\
KO12 & 0,599 & 0,50 & Valid \\
\hline \multicolumn{4}{|c}{ Koefisien reliabilitas $=0,788$} \\
\hline
\end{tabular}

Sumber: Data primer 2010 (diolah).

Hasil uji validitas dan reliabilitas terhadap kuesioner Komitmen organisasional yang disajikan dalam tabel 5 menunjukkan bahwa, masingmasing item pernyataan dalam kuesioner tersebut memiliki koefisien validitas $>0,50$; sehingga dapat disimpulkan bahwa masing-masing item pernyataan tersebut valid.

Koefisien reliabilitas kuesioner tersebut sebesar 0,788; oleh karena lebih besar dari 0,60 maka disimpulkan bahwa kuesioner tersebut reliabel. Hasil uji validitas dan reliabilitas ini menunjukkan bahwa kuesioner Komitmen organisasional layak digunakan sebagai instrumen pengumpul data.

\section{Kuesioner Kepuasan Kerja}

Variabel Kepuasan kerja diukur dengan menggunakan 14 item pernyataan.Hasil uji validitas dan reliabilitas terhadap kuesioner tersebut disajikan dalam tabel 6 berikut. 
Tabel 6

\section{Hasil Uji Validitas dan Reliabilitas Kuesioner Kepuasan Kerja}

\begin{tabular}{|c|c|c|c|}
\hline $\begin{array}{c}\text { Item } \\
\text { Pernyataan }\end{array}$ & $\begin{array}{c}\text { Koefisien } \\
\text { Validitas }\end{array}$ & $\begin{array}{c}\text { Nilai } \\
\text { Batas }\end{array}$ & Keterangan \\
\hline KK1 & 0,716 & 0,50 & Valid \\
KK2 & 0,696 & 0,50 & Valid \\
KK3 & 0,635 & 0,50 & Valid \\
KK4 & 0,549 & 0,50 & Valid \\
KK5 & 0,625 & 0,50 & Valid \\
KK6 & 0,660 & 0,50 & Valid \\
KK7 & 0,644 & 0,50 & Valid \\
KK8 & 0,740 & 0,50 & Valid \\
KK9 & 0,543 & 0,50 & Valid \\
KK10 & 0,792 & 0,50 & Valid \\
KK11 & 0,777 & 0,50 & Valid \\
KK12 & 0,624 & 0,50 & Valid \\
KK13 & 0,604 & 0,50 & Valid \\
KK14 & 0,768 & 0,50 & Valid \\
\hline \multicolumn{4}{|c|}{ Koefisien reliabilitas $=0,748$} \\
\hline
\end{tabular}

Sumber: Data primer 2010 (diolah).

Hasil uji validitas dan reliabilitas terhadap kuesioner Kepuasan kerja yang disajikan dalam tabel 6 menunjukkan bahwa, masing-masing item pernyataan dalam kuesioner tersebut memiliki koefisien validitas $>0,50$; sehingga dapat disimpulkan bahwa masing-masing item pernyataan tersebut valid.

Koefisien reliabilitas kuesioner tersebut sebesar 0,748; oleh karena lebih besar dari 0,60 maka disimpulkan bahwa kuesioner tersebut reliabel. Hasil uji validitas dan reliabilitas ini menunjukkan bahwa kuesioner Kepuasan kerja layak digunakan sebagai instrumen pengumpul data.

\section{B. Deskripsi Variabel}

Deskripsi variabel ini betujuan untuk menjelaskan intensitas masing-masing variabel. Deskripsi dilakukan dengan melakukan kategori variabel ke dalam tingkatan-tingkatan sangat baik, baik, cukup baik, tidak baik dan sangat tidak baik. Penentuan suatu variabel ke dalam kategori tersebut didasarkan pada skor rata-rata variabel yang bersangkutan.
Dalam penelitian ini hipotesis penelitian diuji dengan menggunakan hasil analisis regresi.Analisis regresi yang digunakan dalam penelitian ini adalah regresi linier berganda.Ringkasan hasil analisis regresi linier berganda dengan bantuan program SPSS 15.0 disajikan dalam tabel 7 berikut.

Tabel 7

\section{Hasil Analisis Regresi Linier Berganda}

\begin{tabular}{|c|c|c|c|c|}
\hline VariabelBebas & $\begin{array}{c}\text { Koefisien } \\
\text { regresi } \\
\text { (bi) }\end{array}$ & $\begin{array}{c}\text { Koefisien } \\
\text { regresibaku } \\
(\beta)\end{array}$ & $\mathrm{t}_{\text {hitung }}$ & $\mathrm{p}_{\text {value }}$ \\
\hline Konstanta & 11,883 & & & \\
\hline $\begin{array}{c}\text { Internal } \\
\text { communication } \\
\text { (IC) }\end{array}$ & 0,347 & 0,379 & 2,378 & 0,019 \\
\hline $\begin{array}{l}\text { Leadership } \\
\text { (LD) }\end{array}$ & 0,380 & 0,288 & 2,070 & 0,041 \\
\hline $\begin{array}{c}\text { Customer } \\
\text { oriented }(\mathrm{CO})\end{array}$ & 0,834 & 0,410 & 2,279 & 0,025 \\
\hline $\begin{array}{c}\text { Komitmen } \\
\text { organisasional } \\
(\mathrm{KO})\end{array}$ & 0,425 & 0,308 & 3,322 & 0,001 \\
\hline $\begin{array}{c}\text { Kepuasan kerja } \\
(\mathrm{KK})\end{array}$ & 0,597 & 0,433 & 5,584 & 0,001 \\
\hline & $\mathrm{F}_{\text {hitung }}=37$ & $\begin{array}{l}=121 \\
=0,942 \\
84 ; p_{\text {value }}=0,0\end{array}$ & & \\
\hline
\end{tabular}

Sumber: Data primer 2010 (diolah)

Berdasarkan hasil analisis regresi linier berganda dalam tabel 7 maka ditulis model regresi sebagai berikut :

$$
\begin{aligned}
& \mathrm{ISQ}=2,3766+0,347 \mathrm{IC}+0,380 \mathrm{LD}+0,834 \mathrm{CO} \\
& +0,425 \mathrm{KO}+0,597 \mathrm{KK} \\
& \mathrm{ISQ}=\text { Internal service quality } \\
& \mathrm{IC}=\text { Internal communication } \\
& \mathrm{LD}=\text { Leadership } \\
& \mathrm{CO}=\text { Customer oriented } \\
& \mathrm{KO}=\text { Komitmen organisasional } \\
& \mathrm{KK}=\text { Kepuasan kerja }
\end{aligned}
$$


Internal communication, leadership, customer orientation, komitmen organisasional dan kepuasan kerja secara simultan berpengaruh signifikan terhadap internal service quality $(\mathrm{F}=371,784 ; \mathrm{p}=0,000<0,05)$. Koefisien determinasi $\mathrm{R}^{2}=0,942$ atau 94,2\%; hal ini menunjukkan bahwa baik buruknya internal service quality di PT ASA Yogyakarta 94,2\% ditentukan oleh Internal communication, leadership, customer orientation, komitmen organisasional dan kepuasan kerja; sedangkan 5,8\% sisanya disebabkan oleh variabel-variabel lain yang tidak tercakup dalam penelitian ini.

Internal communication secara parsial berpengaruh positif dan signifikan terhadap internal service quality $(\mathrm{t}=2,378 ; \mathrm{p}=0,019<0,05)$. Koefisien regresi internal communication sebesar $\mathrm{b}_{1}=0,347$; hal ini dapat diinterpretasikan bahwa, jika skor internal communication meningkat 1 maka skor internal service quality meningkat 0,347 .

Leadership secara parsial berpengaruh positif dan signifikan terhadap internal service quality $\quad(\mathrm{t}=2,070 ; \quad \mathrm{p}=0,041<0,05)$. Koefisien regresi leadership sebesar $b_{2}=0,380$; hal ini dapat diinterpretasikan bahwa, jika skor leadership meningkat 1 maka skor internal service quality meningkat 0,380 .

Customer oriented secara parsial berpengaruh positif dan signifikan terhadap internal service quality $(\mathrm{t}=2,279 ; \mathrm{p}=0,025<0,05)$. Koefisien regresi customer oriented sebesar $b_{3}=0,834$; hal ini dapat diinterpretasikan bahwa, jika skor customer oriented meningkat 1 maka skor internal service quality meningkat 0,834 .

Komitmen organisasional secara parsial berpengaruh positif dan signifikan terhadap internal service quality $(\mathrm{t}=3,322 ; \mathrm{p}=0,001<0,05)$. Koefisien regresi komitmen organisasional sebesar $\mathrm{b}_{4}=0,425$; hal ini dapat diinterpretasikan bahwa, jika skor komitmen orgnisasional meningkat
1 maka skor internal service quality meningkat 0,425 .

Kepuasan kerja secara parsial berpengaruh positif dan signifikan terhadap internal service quality $(\mathrm{t}=5,584 ; \mathrm{p}=0,000<0,05)$. Koefisien regresi kepuasan kerja sebesar $b_{5}=0,597$; hal ini dapat diinterpretasikan bahwa, jika skor kepuasan kerja meningkat 1 maka skor internal service quality meningkat 0,597.

Di antara variabel independen dalam model regresi, ternyata variabel Kepuasan kerja memiliki nilai koefisien regresi standar atau beta $(\beta)$ paling besar, yaitu 0,433 . Hal ini menunjukkan bahwa variabel kepuasan kerja merupakan variabel yang paling dominan/kuat pengaruhnya terhadap internal service quality.

\section{KESIMPULAN DAN SARAN}

Berdasarkan hasil penelitian maka dapat disimpulkan sebagai berikut

1. Internal communication, leadership, customer orientation, komitmen organisasional dan kepuasan kerja secara simultan berpengaruh signifikan terhadap internal service quality.

2. Internal communication secara parsial berpengaruh positif dan signifikan terhadap internal service quality.

3. Leadership secara parsial berpengaruh positif dan signifikan terhadap internal service quality.

4. Customer oriented secara parsial berpengaruh positif dan signifikan terhadap internal service quality.

5. Komitmen organisasional secara parsial berpengaruh positif dan signifikan terhadap internal service quality.

6. Kepuasan kerja secara parsial berpengaruh positif dan signifikan terhadap internal service quality. 
7. Diantara variabel independen ternyata variabel kepuasan kerja merupakan variabel yang paling dominan/kuat pengaruhnya terhadap internal service quality.

Mengacu pada hasil penelitian, maka saran yang dapat disampaikan kepada pimpinan atau manajemen PT ASA Yogyakarta adalah meningkatkan kepuasan kerja karyawan. Adapun peningkatan kepuasan kerja karyawan di PT Yogyakarta dapat dilakukan melalui cara-cara berikut ini;

1. Meningkatkan kesejahteraan karyawan, baik melalui peningkatan gaji atau tunjangan karyawan.

2. Memperbaiki sistem penghargaan kepada karyawan yang berprestasi.

3. Memperbaiki sistem promosi jabatan yang selama ini dilakukan.

\section{DAFTAR PUSTAKA}

Ariani, D. W. (2003). Manajemen Kualitas: Pendekatan Sisi Kualitatif. Ghalia Indonesia, Jakarta.

Azwar, S. (2006). Penyusunan Skala Psikologi. Pustaka Pelajar, Yogyakarta.

Boshoff, C. and Mels, G. (1996). "A Causal Model to Evaluate The Relationship among Supervision, Role Stress, Organizational Commitment, and Internal Service Quality". European Journal of Marketing, Vol. 29 No. 2, pp. 33-42.

Fletcher, M. (1999). "The Effects of Internal Communication, Leadership and Team Performance on Succesful Service Quality Implementation". Team Performance Management. Vol. 5 No. 5, pp. 150-161.
Gaspers, V. (2005). Total Quality Management. Gramedia Pustaka Utama, Jakarta.

Gujarati, D. N. (2003). Basic Econometric. Fourth Edition, McGraw-Hill, New York

Goetsch, D. L., dan Davis, S. B. (2002). Pengantar Manajemen Mutu: Manajemen Kualitas untuk Produksi, Pemrosesan dan Pelayanan. Edisi Kedua, Jilid 2, Alih bahasa: Benyamin Molan, Erlangga, Jakarta.

Hair, et al. (2006). Multivariate Data Analyisis. Sixth Edition, Prentice-Hall International, New Jersey.

Hallowell, Schlesinger, Jeffery (1996). „Internal Service Quality, Customer and Job Satisfaction: Lingkage and Implications“, HR. Human Resource Planning, Vol. 19 No. 2, pp. 20-31.

Kang, G. D., James, J. and Alexandris, K. (2002). „Measurement of Internal Service Quality: Application of The SERVQUAL battery to Internal Service Quality“, Managing Service Quality. Vol. 12 No. 2, pp. 278291.

Kreitner, R. dan Kinicki, A. (2005). Perilaku Orgnisasi. Edisi Kelima, Buku Kedua, Alih bahasa Erly Suandy, Salemba Empat, Jakarta.

Liliweri, A. (1997). Sosiologi Organisasi. Citra Aditya Bhakti, Bandung.

Pace, R. W., dan Faules, D. F. (1998). Komunikasi Organisasi: Strategi Meningkatkan Kinerja Perusahaan. Remaja Rosda Karya, Bandung.

Robbins, S. (2006). Perilaku Organisasi. Edisi Kesepuluh, Alih bahasa: Benyamin Molan, Indeks, Jakarta. 
Tjiptono, F. (2001). Prinsip-prinisp Total Quality Service. Andi Offset, Yogyakarta.

Tjiptono, F. (2003).Pemasaran Jasa. Bayumedia, Malang.

Sekaran, U. (2003). Business Research Method. Fourth Edition, Joh Wiley \& Sons, New York.

Sugiyono.(2003).MetodePenelitianAdministrasi. Alfabeta, Bandung.

Yukl,G. (2005). Kepemimpinan dalam Organisasi. Edisi Kelima, Alih bahasa: Budi Supriyanto, Indeks Kelompok Gramedia, Jakarta. 